\title{
Bioactivity in an aggrecan 32 mer fragment is mediated via Toll-like receptor 2
}

\begin{tabular}{|r|l|}
\hline Journal: & Arthritis \& Rheumatology \\
\hline Manuscript ID: & Draft \\
\hline Wiley - Manuscript type: & Full Length \\
\hline Complete List of Authors: & $\begin{array}{l}\text { Lees, Sophie; University of Melbourne, ; Murdoch Childrens Research } \\
\text { Institute, } \\
\text { Golub, Suzanne; University of Melbourne, ; Murdoch Childrens Research } \\
\text { Institute, } \\
\text { Last, Karena; University of Melbourne, ; Murdoch Childrens Research } \\
\text { Institute, } \\
\text { Zeng, Weiguang; University of Melbourne, } \\
\text { Jackson, David; University of Melbourne, } \\
\text { Sutton, Philip; University of Melbourne, ; Murdoch Childrens Research } \\
\text { Institute, } \\
\text { Fosang, Amanda; University of Melbourne, Paediatrics; Murdoch Childrens } \\
\text { Research Institute, Arthritis Research Group }\end{array}$ \\
\hline Keywords: & $\begin{array}{l}\text { Cartilage Degradation, Cartilage, Inflammation, Osteoarthritis, } \\
\text { Proteoglycan }\end{array}$ \\
\hline
\end{tabular}


Bioactivity in an aggrecan 32 mer fragment

\section{Bioactivity in an aggrecan 32mer fragment is mediated via Toll-}

\section{like receptor 2}

Amanda J Fosang, BSc. PhD

Sophie Lees, BSc. (Hons)

Suzanne B. Golub, BSc. (Hons)

Karena Last, BSc.

Weiguang Zeng, BSc. PhD

David C Jackson, BSc. PhD

Philip Sutton, BSc. PhD

The study was supported by funding from the National Health and Medical Research Council (Australia) and the Victorian State Government's Operational Infrastructure Support Program.

Corresponding author:

Professor Amanda J Fosang,

University of Melbourne Department of Paediatrics \& Murdoch Childrens Research Institute, Royal Children's Hospital,

Parkville, 3052,

Australia

E: amandajf@unimelb.edu.au

T: +61-3-8341-6466 
Bioactivity in an aggrecan 32 mer fragment

\section{Objectives}

The aim of this study was to determine whether an aggrecan 32mer fragment derived from dual ADAMTS and MMP cleavage in the aggrecan interglobular domain was bioactive, and if so, to elucidate its mechanism of action.

\section{Methods}

Mouse primary chondrocytes, synovial fibroblasts or peritoneal macrophages, human primary chondrocytes, and cells or cell lines from MyD88-deficient and TLR-2-deficient mice were stimulated with synthetic mouse or human 32 mer peptide or scrambled peptide or native, glycosylated 32 mer peptide. Cells stimulated with $32 \mathrm{mer}$ were analysed for changes in mRNA expression by qPCR. Conditioned medium was analysed for levels of IL-6 protein by AlphaLISA or MMP-3 and MMP-13 protein by Western blot. NFאB activation was measured in a luciferase reporter assay.

\section{Results}

Treatment of mouse cells or cartilage explants with 32 mer peptide or scrambled peptide revealed that the $32 \mathrm{mer}$, but not the scrambled peptide, had anti-anabolic, pro-catabolic and pro-inflammatory bioactivity in vitro. Chondrocytes, synovial fibroblasts and macrophages from Myd88-deficient mice failed to respond to 32mer stimulation. A macrophage cell line derived from $T l r 2$-deficient mice also failed to respond to 32 mer stimulation. Stimulation of human chondrocytes with human 32 mer increased the expression of catabolic markers at the mRNA and protein level. Mouse and human chondrocytes stimulated NF- $\kappa$ B activation in a TLR2-dependent reporter assay, and the response of chondrocytes from both species to native, glycosylated $32 \mathrm{mer}$ was similar to the response to synthetic peptides.

\section{Conclusions}

The aggrecan $32 \mathrm{mer}$ is a novel, endogenous ligand of TLR2 with the potential to accelerate cartilage destruction in vivo. 
Bioactivity in an aggrecan 32 mer fragment

Cartilage is a unique, avascular tissue comprised mostly of a collagen II-rich and aggrecan-rich extracellular matrix, with only a sparse population of resident chondrocytes. Aggrecan degradation by metalloproteinases is a property of all arthritides, but is a particular hallmark of osteoarthritis (OA). Similarly, collagen degradation by collagenases, primarily MMP-13 (1), is a critical feature of late-stage OA and is widely considered to mark an irreparable phase of cartilage damage. The aggrecanases and collagenases that degrade cartilage matrix are produced by chondrocytes, synovial fibroblasts (SF) and also infiltrating macrophages, the latter representing as much as $60 \%$ of the inflammatory infiltrate in OA (2).

Toll-like receptors (TLR) have central roles in the innate immune response to pathogens. Pathogen-derived ligand binding to TLRs activates the NF- $\kappa \mathrm{B}$ and MAP kinase pathways which drive production of inflammatory mediators such as IL-1 $\alpha$, IL-6, and TNF $\alpha(3,4)$. In addition, endogenous proteins, nucleic acids and carbohydrates released from injured cells or tissues are also TLR ligands, known as damage-associated molecular patterns (DAMPs) (5). In injured tissues, the DAMP-induced inflammatory response can promote tissue repair, however in disease, self-perpetuating cycles of tissue destruction can lead to episodes of severe, chronic inflammation.

The results from in vivo studies on TLRs and their ligands in the synovium of mice with inflammatory arthritis suggest a critical role for TLRs in the pathogenesis of rheumatoid arthritis (RA)-like disease (6-12). Fewer studies have examined TLRs and their ligands in cartilage and OA, however it is clear that human chondrocytes express TLRs 1-5 (13, 14), that there is differential regulation of TLR2 and TLR3 in normal and OA human cartilage (13) and that pro-arthritic agents can regulate TLR2 activation in vitro (14). The down-regulation of TLR2 expression in human OA is thought to confer protection against an inflammatory insult 
Bioactivity in an aggrecan 32 mer fragment

(13). Several fragmented components of the cartilage matrix, released into the synovial space, are recognised TLR ligands in cartilage $(7,15)$, including low molecular weight HA $(16,17)$, tenascin $\mathrm{C}(18,19)$ and fibronectin $(14,20)$. Other matrix molecules such as the small leucinerich proteoglycans decorin and biglycan (21-23) and the aggrecan-related proteoglycan versican (24) have been identified as TLR ligands in other cell and tissue types, and may also be active in joint tissues (reviewed in (25)). The calcium-binding proteins S100A8 and S100A9 were recently identified as DAMPs present at high concentration in OA joints (26). To date, there are no reports of TLR ligands derived from the major cartilage components, aggrecan or type II collagen.

Aggrecan is a large proteoglycan that, together with type II collagen, confers the weightbearing properties of cartilage, where it is almost exclusively expressed. Several aggrecan fragments comprising the N-terminal globular domains accumulate in cartilage with age (27, 28). Following aggrecanolysis, large glycosaminoglycan-bearing fragments from the aggrecan C-terminus are separated from their anchor to HA, and lost from the cartilage matrix, whereas a range of fragments from the aggrecan N-terminus (29) are retained in the tissue by binding to HA via the first globular $(\mathrm{G} 1)$ domain. G1-containing fragments produced by proteinase cleavage in the interglobular domain (IGD) include G1-EGE ${ }^{373}$ produced by ADAMTS cleavage at $\mathrm{E}^{373} \downarrow^{374} \mathrm{~A}(30,31)$ and $\mathrm{G} 1-\mathrm{PEN}^{341}$ produced by MMP cleavage at $\mathrm{N}^{341} \downarrow^{342} \mathrm{~F}(32$ 34). The G1-EGE ${ }^{373}$ fragment is the substrate for 32 mer production and the $32 \mathrm{mer}$ is the product of MMP activity.

Primary bovine chondrocytes cultured in the presence of exogenous G1-EGE ${ }^{373}$ internalise this G1 fragment via HA-mediated binding to CD44 (35). Thereafter, epitopes associated with the G1 domain localise in intracellular vesicles, whereas $\mathrm{EGE}^{373}$ neoepitopes are detected in the 
Bioactivity in an aggrecan 32 mer fragment

nucleus (35), independent of the G1 domain This intriguing finding led us to hypothesise that a G1-deficient, EGE ${ }^{373}$-containing peptide(s), most likely the aggrecan 32mer, has a biological function in vivo. In the present study, we have identified the aggrecan 32mer fragment as a naturally-occurring TLR2 ligand in chondrocytes, synovial fibroblasts and macrophages.

\section{MATERIALS AND METHODS}

\section{Reagents}

Synthetic mouse 32mer peptide (FFGVGGEDDITIQTVTWPDLELPLPRNVTEGE) and a scrambled peptide (LPTFGEVEVWLLGEDQDFDIPTTVGPRTGEIN) with the same amino acids but with no homology to any known protein were from Auspep, Parkville, Australia. The human 32mer peptide (FFGVGGEEDITVQTVTWPDMELPLPRNITEGE) was prepared with free N- and C-termini using Fmoc chemistry on a microwave-assisted Liberty automatic peptide synthesizer. The crude peptide was purified on a C8 reverse-phase column and the structure was confirmed by electrospray mass spectrometry and from amino acid analysis. Peptides in PBS were used at the concentrations shown. Native, glycosylated 32mer was isolated from pig articular cartilage as described previously (36). IL-1 $\alpha$ was from Peprotech, (NJ, USA). TK-Renilla-luciferase expressing plasmid, Reporter lysis buffer and reagent kit were from Promega corporation, Madison, USA. Fugene 6 was from Roche Diagnostic. Lipopolysaccharide (LPS) was from Invitrogen (San Diego, USA)

\section{Primary cells, cell lines $\&$ human tissue}

Procedures involving mice were approved by the Murdoch Childrens Research Institute Animal Ethics Committee. Mouse epiphyseal chondrocytes were prepared as described previously (37). Mouse synovial fibroblasts were prepared as outgrowth cultures from 
Bioactivity in an aggrecan 32 mer fragment

explanted mouse patellae harvested from knee joints at 11-22wks of age. The patellae were cultured in DMEM with $10 \%$ FCS and antibiotics for 3-4 weeks to allow the synovial fibroblasts to migrate away from the explants and form monolayers. Non-migratory chondrocytes were not detected in the cell monolayers. The synovial fibroblasts were expanded in culture for $\sim 3$ weeks, then $0.5 \times 10^{6}$ cells were seeded into 48 well plates prior to treatment.

Peritoneal macrophages were harvested at $11-22$ wk of age by flushing the peritoneum of culled mice. After gently agitating the abdomen, 8-10mls of ice cold PBS with $2 \%$ FBS was injected and peritoneal cells were collected and centrifuged at $1500 \mathrm{rpm}$. Cells $\left(10^{6}\right.$ cells $\left./ 500 \mu \mathrm{L}\right)$ in RPMI with $10 \%$ FBS were incubated for 2 hours at $37^{\circ} \mathrm{C}$ in 48 well plates. Non-adherent contaminating cells were discarded and adherent macrophages cultured overnight at $37^{\circ} \mathrm{C}$ in fresh medium, prior to treatment. Immortalised macrophage cell lines derived from the bone marrow of wildtype or Tlr2-deficient mice were those described previously (38) and made available by Dr Eicke Latz, University of Bonn, Germany, via Dr Ashley Mansell, Monash Institute for Medical Research, Australia. The cells were cultured in DMEM with 10\% FBS for 4-5 days before treating for 24 hours with peptides, IL-1 $\alpha$ or LPS.

Human femoral head cartilage with normal, healthy appearance was obtained from a 13 year old male patient undergoing joint replacement surgery for spondyloepiphyseal dysplasia at the Royal Children's Hospital, Melbourne, Australia. Chondrocytes prepared from fresh cartilage slices were cultured for 3 days prior to treatment for 24 hours.

\section{Quantitative reverse transcription (RT-PCR) analysis of mRNA expression}

mRNA expression was analysed by real-time quantitative PCR (qPCR) with probes and

primers from the Universal Probes Library (UPL) (Roche, Basel, Switzerland). The $\Delta \Delta \mathrm{Cp}$ 
Bioactivity in an aggrecan 32 mer fragment

values, derived from the $\mathrm{Cp}$ values calculated by the Roche Light Cycler 480, were calculated for each gene and normalized against the geometric mean of two cell type-specific reference genes (39). The relative $\Delta \Delta \mathrm{Cp}$ values for mouse chondrocytes were normalized against the geometric mean of the genes $R p l 10$ and $R p l 26$, for synovial fibroblasts, against the geometric mean of Mrps16 and Atp5b and in peritoneal macrophages against Hprt1 and Ppia. The relative $\Delta \Delta \mathrm{Cp}$ values for human chondrocytes were normalized against the geometric mean of the genes RPL10 and ATP5B. The primer sequences used for the genes specified are shown in Table 1.

\section{IL-6 ELISA, Western blotting and luciferase reporter assay}

The concentration of mouse IL- 6 in conditioned media was assayed by the mouse IL-6 AlphaLISA (Perkin Elmer, MA, USA). The range of the assay was $1.6-300,000 \mathrm{pg} / \mathrm{mL}$. A luciferase reporter assay was as described previously (40). Sheep polyclonal antibodies against human MMP-3 and human MMP-13were generous gifts from Prof Gillian Murphy and Dr Vera Knäuper as described previously (41).

\section{RESULTS}

To test our hypothesis that the 32 mer was a bioactive aggrecan fragment, we treated primary mouse chondrocytes with mouse 32 mer peptide for 24 hours in a dose-response experiment (1$300 \mu \mathrm{M})$ and measured changes in mRNA expression of matrix proteins, metalloproteinases, signalling molecules, cytokines and chemokines by qPCR. We predicted that the 32 mer would stimulate an anabolic response in chondrocytes, to redress the catabolic event(s) that had caused its release. Surprisingly, the results revealed a dose-dependent increase in the expression of pro-catabolic and pro-inflammatory genes including Mmp13, Mmp12, Il6 and

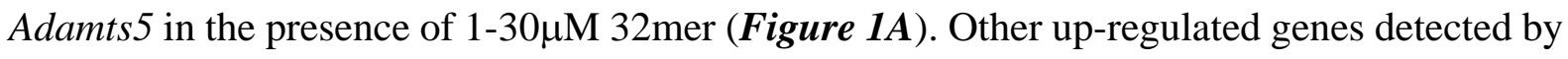


Bioactivity in an aggrecan 32 mer fragment

qPCR included Inos, Mmp14, Mmp8 and Ccl2 (data not shown). To confirm that the effects of the 32 mer on mRNA expression were specific, we compared expression levels relative to treatment with a 32 mer scrambled peptide. Figure $1 B$ shows that the scrambled peptide had a negligible effect, or no effect, on mRNA expression, confirming that the response of mouse chondrocytes to mouse 32 mer peptide was specific. Importantly, the level of up-regulated gene expression in IL-1 $\alpha$-treated samples was similar to the level induced by the 32 mer peptide (Figure 1B). Since native 32mer detected in human synovial fluid (42) or purified from pig articular cartilage(43) contains a substantial amount of keratan sulphate (KS) we also analysed mouse chondrocytes for their response to native, glycosylated pig $32 \mathrm{mer}$ and found that it also increased the expression of pro-catabolic and pro-inflammatory genes, including Mmp13 and Ccl2 (Figure 1C).

At higher concentrations of $32 \mathrm{mer}(100-300 \mu \mathrm{M})$ we detected a dose-dependent downregulation of genes encoding matrix-building proteins, including col2al, Matl1, Col11al and Fmod (Figure 2A). Other genes down-regulated by high concentrations of $32 \mathrm{mer}$ included Agcn, Col9a1, Colloal, Pcolce2, Dlk1 (data not shown). Again, to confirm that the 32mer effects on mRNA expression were specific, we compared expression levels relative to treatment with a 32 mer scrambled peptide and found that there was little or no effect of the scrambled peptide on the expression of matrix building genes including Col2al, Matll, Agcn and Fmod Figure $2 \boldsymbol{B}$ ), and also that the level of down-regulated mRNA expression induced by the $32 \mathrm{mer}$, was similar to that induced by IL-1 $\alpha$ (Figure $2 \boldsymbol{B}$ ).

The similarity in the mRNA expression profiles and the extent to which individual genes were up- or down-regulated by 32 mer treatment compared with IL-1 $\alpha$, suggested that 32 mer bioactivity might be mediated by a member of the IL-1 receptor family, all of which are 
Bioactivity in an aggrecan 32 mer fragment

dependent on the adaptor protein MyD88. We therefore treated chondrocytes, synovial fibroblasts and peritoneal macrophages harvested from wildtype or Myd88-deficient mice with mouse $32 \mathrm{mer}$ and scrambled peptide for 24 hours and measured the mRNA expression of Mmp12, Mmp13 and Adamts in mouse chondrocytes (Figure 3A), Mmp12, Mmp13 and Il6 in mouse synovial fibroblasts (Figure 3B), and Il $\alpha, I L 10$ and $C c l 2$ (Figure $4 I$ ) by qPCR. IL-1 $\alpha$ or LPS stimulations were included as positive controls.

The results of these experiments confirmed that for wildtype chondrocytes and synovial fibroblasts mRNA expression of Mmp12, Mmp13, Adamts5 and Il6 was increased in response to $32 \mathrm{mer}$ and IL-1 $\alpha$ treatment, however the response of these cell types to the scrambled peptide was absent or blunted, as expected. Macrophages from wildtype mice also increased their mRNA expression of selected genes, including Illa, IllO and Ccl2 (Figure 3C) in response to treatment with the 32 mer or LPS, but they had little or no response to the scrambled peptide (Figure $3 C$ ). In contrast to the wildtype cells, chondrocytes, synovial fibroblasts and macrophages from the $M y d 88$-deficient mice failed to respond to the mouse 32 mer peptide (Figure 3). The Myd88-deficient macrophages also failed to respond to LPS as expected (Figure 3). These results raised the possibility that the $32 \mathrm{mer}$ is a hitherto unrecognised, cartilage-specific DAMP derived from proteolysis of aggrecan.

Since DAMPs mediate their actions via Toll-like receptors, and since TLR2 activation has previously been linked with arthritis pathology, we compared macrophage cell lines derived from wildtype or $T l r 2$-deficient mice for their response to the $32 \mathrm{mer}$ peptide by measuring changes in mRNA expression of Il6 and Inos by qPCR (Figure 4A,C) and levels of IL-6 protein by ELISA (Figure $4 \boldsymbol{B}$ ). The results showed clearly that the $T l r 2$-deficient cell line failed to respond to the $32 \mathrm{mer}$ peptide at both the mRNA and the protein level, and suggesting therefore 
Bioactivity in an aggrecan 32 mer fragment

that the aggrecan 32mer is a ligand for TLR2. Failure of the Tlr2-deficient macrophage cell line to respond to the $32 \mathrm{mer}$ also suggests that the $32 \mathrm{mer}$ is unlikely to be a TLR4 ligand, since TLR4 is not disrupted in the TLR2-deficient cells.

We next tested whether the human 32 mer peptide is active in human cartilage. The results of a dose-response experiment showed that human chondrocytes increased their expression of mRNA encoding IL6 and MMP13 (Figure 5A) in response to human 32mer. Furthermore the native, glycosylated 32mer fragment also stimulated the increased expression of CCL2, IL6 (Figure 6D), MMP3 and MMP13 (Figure 5B) in human chondrocytes. Western blot analysis of conditioned medium harvested from the human chondrocyte cultures after stimulation with human 32mer revealed increased levels of active MMP3 and MMP13(Figure 5C) protein to levels that were greater than the untreated explants, but not as high as samples treated with IL$1 \alpha$.

Finally, we measured 32mer-induced NF- $\kappa$ B activation in a TLR2-dependent NF- $\kappa$ B luciferase reporter assay, using both mouse and human 32mer peptides to stimulate HEK293 cells transfected with a TLR2-expressing plasmid. As predicted, cells in the reporter assay failed to activate NF- $\kappa \mathrm{B}$ in response to the scrambled peptide, however both mouse and human 32mer, at $12.5 \mathrm{uM}$, stimulated $\mathrm{NF}-\mathrm{\kappa B}$ reporter activity (Figure 5D). This experiment showed that the human peptide was more active than the mouse peptide, however the hierarchy of stimulation between mouse and human peptides varied slightly between different experiments (data not shown). 
Bioactivity in an aggrecan 32mer fragment

\section{DISCUSSION}

DAMPs and Toll-like receptors are considered important modulators of the disease process in inflammatory arthritis (reviewed in $(6,8)$ ). Several models of inflammatory arthritis in mice involve TLR-mediated synovial activation $(9,10,44)$ that is thought to drive the disease process, and based on the results of these studies, TLR antagonists are in development for the management of RA (6). However, interest in TLR activation by endogenous ligands in OA is relatively recent, and emerges from the new paradigm that $\mathrm{OA}$ is associated with chronic, lowlevels of inflammation and synovitis (45-47). Our finding that the aggrecan 32mer is a TLR2 ligand that induces MMP and cytokine expression is consistent with other studies that have identified TLR2, 3 and 4-dependent increases in collagenase activity and cartilage resorption, as well as TLR4-dependent down regulation of aggrecan and collagen expression using traditional bacterial ligands such as LPS $(13,48)$. The most novel and important aspect of the present study is that the activating ligand that stimulates these same catabolic and inflammatory pathways (albeit to lower levels than for LPS) is an endogenous peptide fragment, derived directly, and possibly exclusively, from cartilage. Further work is required to determine whether the aggrecan 32mer might also signal through other TLRs, interact with other accessory proteins, for example soluble CD14 (49), and synergise with other catabolic agents, such as oncostatin M (13), to induce even greater levels of cartilage resorption.

A recent mouse study comparing the role of TLR2 in contrasting models of experimental OA showed that whereas $T l r 2$-deficiency exacerbated disease severity in the highly inflammatory collagenase-induced model of OA, the non-inflammatory, destabilisation of the medial meniscus (DMM model) showed no difference in disease severity between wildtype and Tlr2deficient mice (50). These results, which suggest a protective role for TLR2 in collagenaseinduced OA, seemed counter-intuitive at the time, however it now seems likely that the 
Bioactivity in an aggrecan 32 mer fragment

different outcomes reflect the different inflammatory load each model delivers to the affected joint. In the future it will be important to investigate activation of TLR2, and indeed other Tolllike receptors, in longer-term models of non-inflammatory and trauma-induced OA that more closely resemble the human situation.

In contrast to the aggressive inflammation that typifies RA, the hallmark of OA is radiographic joint space narrowing caused by proteinase-driven cartilage erosion in a relatively mild inflammatory environment. Cartilage erosion in OA can progress for many years as subclinical disease. Since type II collagen in mature human cartilage has a half-life of $\sim 117$ years (51), any significant damage to the collagen network is widely considered to be irreparable (52). Data from mouse models of arthritis have confirmed that cartilage can withstand only a limited degree of type II collagen degradation before the onset of irreversible damage (53). In contrast, large glycosaminoglycan-bearing aggrecan fragments lost from cartilage following normal or stimulated aggrecanolysis in vivo, are readily replaced by newly synthesised aggrecan (54). Because aggrecanases cleave at G1-EGE ${ }^{373 \downarrow 374}$ ARG, and because G1-EGE ${ }^{373}$ (32mer substrate) is retained in the cartilage matrix, repeated cycles of glycosaminoglycan loss coupled with new aggrecan synthesis will lead to an accumulation of G1-EGE ${ }^{373}$, and the rate of accumulation will increase proportional with the rate of aggrecanolysis. Accordingly, since the concentration of aggrecan (glycosaminoglycan) in normal cartilage is approximately $25 \mu \mathrm{M}$, the micromolar concentrations of 32 mer used in this study might be physiological under certain conditions. The half-life of aggrecan G1-domains in adult cartilage is $\sim 24$ years (27), nearly 7 times longer than for intact aggrecan (28).

Native 32mer present in human synovial fluids $(42,55)$ ranges in size from $\mathrm{Mr}$ 35,000-70,000, depending on the extent of KS substitution present on amino acids $\mathrm{T}^{352}, \mathrm{~T}^{357}, \mathrm{~N}^{368}$ and $\mathrm{T}^{370}$; 
Bioactivity in an aggrecan 32mer fragment

these residues are strictly conserved in mammalian aggrecan (56). KS in the aggrecan IGD of young pigs is uniquely under-sulphated compared with that in the KS-rich region of aggrecan (36), however KS in the IGD of other species has not been examined. The significance of the sulphation patterns on native $32 \mathrm{mer}$, and its influence on ligand binding to TLR2, and indeed other potential binding partners in the OA joint is presently unclear. Further studies to examine the level and pattern of KS sulphation in the human 32mer, whether it changes with age (as for the KS-rich region in humans) (57) or disease, and the impact of different glycosylation profiles on TLR activation is warranted.

In summary, we have discovered that a naturally-occurring aggrecan fragment is an NF- $\mathrm{B}$ activating, TLR2 ligand that stimulates pro-inflammatory and pro-catabolic activities. The aggrecan 32mer is an important addition to the list of joint-relevant and OA-relevant DAMPs, especially because it is renewable within the cartilage matrix and is derived from a precursor with a long tissue half-life. Based on its signalling via TLR2, and activation of NF- $\kappa \mathrm{B}$ in vitro, the aggrecan 32 mer has a putative role in exacerbating inflammation in joint disease and potentially, in other aggrecan-expressing tissues such as nerves and brain. We speculate that MMP-13 inhibitors in development as collagen II-protective agents in OA may find additional utility in reducing joint inflammation and synovitis by blocking MMP-dependent 32mer production.

\section{Acknowledgements}

We sincerely thank Mr Leo Donnan, Royal Children's Hospital, Melbourne, Australia, for providing human cartilage. We are grateful to Dr Katrina Bell and Dr Jovana Maksimovic for their contributions to the early design and interpretation of preliminary data generated for this 
Bioactivity in an aggrecan 32 mer fragment

work. The study was supported by funding from the National Health and Medical Research

Council and the Victorian State Government's Operational Infrastructure Support Program.

Table 1. qPCR primers

\begin{tabular}{|c|c|c|c|}
\hline Species & Gene & Primer & Sequence \\
\hline \multirow[t]{24}{*}{ Mouse } & Adamts 5 & $\mathrm{~F}$ & 5'-atgcagccatcctgtttcac-3' \\
\hline & & $\mathrm{R}$ & 5'-cattcccagggtgtcacat-3' \\
\hline & Mmpl2 & $\mathrm{F}$ & 5'-ttgtggataaacactactggaggt-3' \\
\hline & & $\mathrm{R}$ & 5'aaatcagcttggggtaagca3' \\
\hline & Mmp13 & $\mathrm{F}$ & 5'-tcaaggctatgcacactggt-3' \\
\hline & & $\mathrm{R}$ & 5'-cactatggtcttttcaatgcctaa-3' \\
\hline & Mmp3 & $\mathrm{F}$ & 5'-ttgttctttgatgcagtcagc-3' \\
\hline & & $\mathrm{R}$ & 5'-gatttgcgccaaaagtgc-3' \\
\hline & Il6 & $\mathrm{F}$ & 5 '-tgatggatgctaccaaactgg-3' \\
\hline & & $\mathrm{R}$ & 5'-ttcatgtactccaggtagctatgg-3' \\
\hline & Inos & $\mathrm{F}$ & 5'-tgaacttgagcgaggagca-3' \\
\hline & & $\mathrm{R}$ & 5'-ttcatgataacgtttctggctct-3' \\
\hline & Ccl2 & $\mathrm{F}$ & 5'-catccacgtgttggctca-3' \\
\hline & & $\mathrm{R}$ & 5'-gatcatcttgctggtgaatgagt-3' \\
\hline & Col2al & $\mathrm{F}$ & 5'-ctgccagtggaaaattaggg-3' \\
\hline & & $\mathrm{R}$ & 5'-ggaggtcctctgggtcctat-3' \\
\hline & Coll1a1 & $\mathrm{F}$ & 5'-ccagcagaaactgatttcacag-3' \\
\hline & & $\mathrm{R}$ & 5'-ttcaaccacagccggttc-3' \\
\hline & Matll & $\mathrm{F}$ & 5'-tccctgatagcctcagtcttg-3' \\
\hline & & $\mathrm{R}$ & 5'-tcgacaacaaacaccaggtc-3' \\
\hline & Fmod & $\mathrm{F}$ & 5'-cagggcaacaggatcaatg-3' \\
\hline & & $\mathrm{R}$ & 5'-ctgcagcttggagaagttcat-3' \\
\hline & Agcn & $\mathrm{F}$ & 5'-agtgcactgagggctttgtc-3' \\
\hline & & $\mathrm{R}$ & 5'-gtaggtgttggggtctgtgc-3' \\
\hline \multirow[t]{2}{*}{ Human } & IL6 & $\mathrm{F}$ & 5'-ctgacccaaccacaaatgc-3' \\
\hline & & $\mathrm{R}$ & 5'-ctgcagccactggttctgt-3' \\
\hline
\end{tabular}


Bioactivity in an aggrecan 32 mer fragment

\section{References}

1. Mitchell PG, Magna HA, Reeves LM, Lopresti-Morrow LL, Yocum SA, Rosner PJ, et al. Cloning, expression, and type II collagenolytic activity of matrix metalloproteinase-13 from human osteoarthritic cartilage. JClinInvest. 1996;97:761-8.

2. de Lange-Brokaar BJ, Ioan-Facsinay A, van Osch GJ, Zuurmond AM, Schoones J, Toes RE, et al. Synovial inflammation, immune cells and their cytokines in osteoarthritis: a review. Osteoarthritis Cartilage. 2012;20(12):1484-99.

3. Aderem A, Ulevitch RJ. Toll-like receptors in the induction of the innate immune response. Nature. 2000;406(6797):782-7.

4. Kaisho T, Akira S. Dendritic-cell function in Toll-like receptor- and MyD88knockout mice. Trends Immunol. 2001;22(2):78-83.

5. Foell D, Wittkowski H, Roth J. Mechanisms of disease: a 'DAMP' view of inflammatory arthritis. Nat Clin Pract Rheumatol. 2007;3(7):382-90.

6. Page TM, K.S. Targeting DAMP activation of Toll-like receptors: novel pathways to treat rheumatoid arthritis? In: Lemmey A, editor. Rheumatoid Arthritis-Treatment: In Tech; 2012. p. 211-32.

7. Scanzello CR, Goldring SR. The role of synovitis in osteoarthritis pathogenesis. Bone. 2012;51(2):249-57.

8. Goh FG, Midwood KS. Intrinsic danger: activation of Toll-like receptors in rheumatoid arthritis. Rheumatology (Oxford). 2012;51(1):7-23.

9. Choe JY, Crain B, Wu SR, Corr M. Interleukin 1 receptor dependence of serum transferred arthritis can be circumvented by toll-like receptor 4 signaling. J Exp Med. 2003;197(4):537-42. 
Bioactivity in an aggrecan 32 mer fragment

10. Abdollahi-Roodsaz S, Joosten LA, Koenders MI, Devesa I, Roelofs MF, Radstake TR, et al. Stimulation of TLR 2 and TLR4 differentially skews the balance of T cells in a mouse model of arthritis. J Clin Invest. 2008;118(1):205-16.

11. Kyo F, Futani H, Matsui K, Terada M, Adachi K, Nagata K, et al. Endogenous interleukin-6, but not tumor necrosis factor alpha, contributes to the development of toll-like receptor 4/myeloid differentiation factor 88-mediated acute arthritis in mice. Arthritis Rheum. 2005;52(8):2530-40.

12. Ronaghy A, Prakken BJ, Takabayashi K, Firestein GS, Boyle D, Zvailfler NJ, et al. Immunostimulatory DNA sequences influence the course of adjuvant arthritis. J Immunol. 2002;168(1):51-6.

13. Zhang Q, Hui W, Litherland GJ, Barter MJ, Davidson R, Darrah C, et al. Differential Toll-like receptor-dependent collagenase expression in chondrocytes. Ann Rheum Dis. 2008;67(11):1633-41.

14. Su SL, Tsai CD, Lee CH, Salter DM, Lee HS. Expression and regulation of Toll-like receptor 2 by IL-1beta and fibronectin fragments in human articular chondrocytes. Osteoarthritis Cartilage. 2005;13(10):879-86.

15. Sillat T, Barreto G, Clarijs P, Soininen A, Ainola M, Pajarinen J, et al. Toll-like receptors in human chondrocytes and osteoarthritic cartilage. Acta Orthop. 2013;84(6):58592.

16. Liu-Bryan R, Terkeltaub R. Chondrocyte innate immune myeloid differentiation factor 88-dependent signaling drives procatabolic effects of the endogenous Toll-like receptor 2/Toll-like receptor 4 ligands low molecular weight hyaluronan and high mobility group box chromosomal protein 1 in mice. Arthritis Rheum. 2010;62(7):2004-12. 
Bioactivity in an aggrecan 32mer fragment

17. Termeer C, Benedix F, Sleeman J, Fieber C, Voith U, Ahrens T, et al.

Oligosaccharides of Hyaluronan activate dendritic cells via toll-like receptor 4. The Journal of experimental medicine. 2002;195(1):99-111.

18. Chevalier X, Groult N, Larget-Piet B, Zardi L, Hornebeck W. Tenascin distribution in articular cartilage from normal subjects and from patients with osteoarthritis and rheumatoid arthritis. Arthritis Rheum. 1994;37(7):1013-22.

19. Midwood K, Sacre S, Piccinini AM, Inglis J, Trebaul A, Chan E, et al. Tenascin-C is an endogenous activator of Toll-like receptor 4 that is essential for maintaining inflammation in arthritic joint disease. Nat Med. 2009;15(7):774-80.

20. Gondokaryono SP, Ushio H, Niyonsaba F, Hara M, Takenaka H, Jayawardana ST, et al. The extra domain A of fibronectin stimulates murine mast cells via toll-like receptor 4 . $\mathrm{J}$ Leukoc Biol. 2007;82(3):657-65.

21. Schaefer L, Babelova A, Kiss E, Hausser HJ, Baliova M, Krzyzankova M, et al. The matrix component biglycan is proinflammatory and signals through Toll-like receptors 4 and 2 in macrophages. J Clin Invest. 2005;115(8):2223-33.

22. Bock HC, Michaeli P, Bode C, Schultz W, Kresse H, Herken R, et al. The small proteoglycans decorin and biglycan in human articular cartilage of late-stage osteoarthritis. Osteoarthritis Cartilage. 2001;9(7):654-63.

23. Merline R, Moreth K, Beckmann J, Nastase MV, Zeng-Brouwers J, Tralhao JG, et al. Signaling by the matrix proteoglycan decorin controls inflammation and cancer through PDCD4 and MicroRNA-21. Sci Signal. 2011;4(199):ra75.

24. Kim S, Takahashi H, Lin WW, Descargues P, Grivennikov S, Kim Y, et al. Carcinoma-produced factors activate myeloid cells through TLR2 to stimulate metastasis. Nature. 2009;457(7225):102-6. 
Bioactivity in an aggrecan 32 mer fragment

25. Piccinini AM, Midwood KS. DAMPening inflammation by modulating TLR signalling. Mediators Inflamm. 2010;2010.

26. Schelbergen RF, Blom AB, van den Bosch MH, Sloetjes A, Abdollahi-Roodsaz S, Schreurs BW, et al. Alarmins S100A8 and S100A9 elicit a catabolic effect in human osteoarthritic chondrocytes that is dependent on Toll-like receptor 4. Arthritis Rheum. 2012;64(5):1477-87.

27. Verzijl N, DeGroot J, Bank RA, Bayliss MT, Bijlsma JW, Lafeber FP, et al. Agerelated accumulation of the advanced glycation endproduct pentosidine in human articular cartilage aggrecan: the use of pentosidine levels as a quantitative measure of protein turnover. Matrix Biol. 2001;20(7):409-17.

28. Maroudas A, Bayliss MT, Uchitel-Kaushansky N, Schneiderman R, Gilav E. Aggrecan turnover in human articular cartilage: use of aspartic acid racemization as a marker of molecular age. ArchBiochemBiophys. 1998;350(1):61-71.

29. Vilím V, Fosang AJ. Proteoglycans isolated from dissociative extracts of differentlyaged human articular cartilage: Characterization of naturally-occuring hyaluronan-binding fragments of aggrecan. BiochemJ. 1994;304:887-94.

30. Abbaszade I, Liu RQ, Yang F, Rosenfeld SA, Ross OH, Link JR, et al. Cloning and Characterization of ADAMTS11, an Aggrecanase from the ADAMTS Family. JBiolChem. 1999;274(33):23443-50.

31. Tortorella MD, Burn TC, Pratta MA, Abbaszade I, Hollis JM, Liu R, et al. Purification and Cloning of Aggrecanase-1: A Member of the ADAMTS Family of Proteins. Science. 1999;284(5420):1664-6.

32. Fosang AJ, Neame PJ, Hardingham TE, Murphy G, Hamilton JA. Cleavage of cartilage proteoglycan between G1 and G2 domains by stromelysins. JBiolChem. 1991;266:15579-82. 
Bioactivity in an aggrecan 32mer fragment

33. Fosang AJ, Neame PJ, Last K, Hardingham TE, Murphy G, Hamilton JA. The interglobular domain of cartilage aggrecan is cleaved by Pump, gelatinases and cathepsin B. JBiolChem. 1992;267:19470-4.

34. Fosang AJ, Last K, Knäuper V, Murphy G, Neame PJ. Degradation of cartilage aggrecan by collagenase-3 (MMP-13). FEBS Lett. 1996;380:17-20.

35. Embry Flory JJ, Fosang AJ, Knudson W. The accumulation of intracellular ITEGE and DIPEN neoepitopes in bovine articular chondrocytes is mediated by CD44 internalization of hyaluronan. Arthritis Rheum. 2006;54(2):443-54.

36. Fosang AJ, Last K, Poon CJ, Plaas AH. Keratan sulphate in the interglobular domain has a microstructure that is distinct from keratan sulphate elsewhere on pig aggrecan. Matrix Biol. 2009;28(1):53-61.

37. Rogerson FM, Chung YM, Deutscher ME, Last K, Fosang AJ. Cytokine-induced increases in ADAMTS-4 messenger RNA expression do not lead to increased aggrecanase activity in ADAMTS-5-deficient mice. Arthritis Rheum. 2010;62(11):3365-73.

38. Hornung V, Bauernfeind F, Halle A, Samstad EO, Kono H, Rock KL, et al. Silica crystals and aluminum salts activate the NALP3 inflammasome through phagosomal destabilization. Nat Immunol. 2008;9(8):847-56.

39. Vandesompele J, De Preter K, Pattyn F, Poppe B, Van Roy N, De Paepe A, et al. Accurate normalization of real-time quantitative RT-PCR data by geometric averaging of multiple internal control genes. Genome Biol. 2002;3(7):RESEARCH0034.

40. Zeng W, Eriksson E, Chua B, Grollo L, Jackson DC. Structural requirement for the agonist activity of the TLR2 ligand Pam2Cys. Amino acids. 2010;39(2):471-80.

41. Stanton H, Ung L, Fosang AJ. The $45 \mathrm{kDa}$ collagen-binding fragment of fibronectin induces matrix metalloproteinase-13 synthesis by chondrocytes and aggrecan degradation by aggrecanases. Biochem J. 2002;364(Pt 1):181-90. 
Bioactivity in an aggrecan 32 mer fragment

42. Fosang AJ, Last K, Gardiner P, Jackson DC, Brown L. Development of a cleavage site-specific monoclonal antibody for detecting metalloproteinase-derived aggrecan fragments: detection of fragments in human synovial fluids. BiochemJ. 1995;310:337-43.

43. Fosang AJ. MMP GRC program and my notes and participant list. 2009.

44. Leung BP, Xu D, Culshaw S, McInnes IB, Liew FY. A novel therapy of murine collagen-induced arthritis with soluble T1/ST2. J Immunol. 2004;173(1):145-50.

45. Liu-Bryan R, Terkeltaub R. The growing array of innate inflammatory ignition switches in osteoarthritis. Arthritis Rheum. 2012;64(7):2055-8.

46. Goldring MB, Otero M. Inflammation in osteoarthritis. Curr Opin Rheumatol. $2011 ; 23: 471-8$.

47. Sellam J, Berenbaum F. The role of synovitis in pathophysiology and clinical symptoms of osteoarthritis. Nat Rev Rheumatol. 2010;6(11):625-35.

48. Kim HA, Cho ML, Choi HY, Yoon CS, Jhun JY, Oh HJ, et al. The catabolic pathway mediated by Toll-like receptors in human osteoarthritic chondrocytes. Arthritis Rheum. 2006;54(7):2152-63.

49. Nair A, Kanda V, Bush-Joseph C, Verma N, Chubinskaya S, Mikecz K, et al. Synovial fluid from patients with early osteoarthritis modulates fibroblast-like synoviocyte responses to toll-like receptor 4 and toll-like receptor 2 ligands via soluble CD14. Arthritis Rheum. 2012;64(7):2268-77.

50. Blom A, van Lent P, Abdollahi-Roodsaz S, van der Kraan PM, van den Berg WB. Toll-like receptor-2 activation prevents caartilage damage in osteoarthritis models that display synovial activation (abstract). Arthritis Rheum; 2011. p. 976.

51. Verzij1 N, DeGroot J, Thorpe SR, Bank RA, Shaw JN, Lyons TJ, et al. Effect of collagen turnover on the accumulation of advanced glycation end products. J Biol Chem. 2000;275(50):39027-31. 
Bioactivity in an aggrecan 32mer fragment

52. Zhen EY, Brittain IJ, Laska DA, Mitchell PG, Sumer EU, Karsdal MA, et al. Characterization of metalloprotease cleavage products of human articular cartilage. Arthritis Rheum. 2008;58(8):2420-31.

53. Stoop R, van der Kraan PM, Buma P, Hollander AP, Poole AR, Van Den Berg WB. Denaturation of type II collagen in articular cartilage in experimental murine arthritis.

Evidence for collagen degradation in both reversible and irreversible cartilage damage. JPathol. 1999;188(3):329-37.

54. Thomas L. Reversible collapse of rabbit ears after intravenous papain, and prevention of recovery by cortisone. JExpMedicine. 1956;104:245-61.

55. Fosang AJ, Last K, Maciewicz RA. Aggrecan is degraded by matrix metalloproteinases in human arthritis. Evidence that matrix metalloproteinase and aggrecanase activities can be independent. J Clin Invest. 1996;98:2292-9.

56. Flannery CR, Little CB, Caterson B. Molecular cloning and sequence analysis of the aggrecan interglobular domain from porcine, equine, bovine and ovine cartilage: comparison of proteinase-susceptible regions and sites of keratan sulfate substitution. Matrix Biol. 1998;16(8):507-11.

57. Brown GM, Huckerby TN, Bayliss MT, Nieduszynski IA. Human aggrecan keratan sulfate undergoes structural changes during adolescent development. JBiolChem. 1998;273(41):26408-14.

\section{Figure Legends}

Figure 1. Increased mRNA expression of pro-inflammatory and pro-catabolic genes induced by 32mer treatment of primary mouse chondrocytes. A) qPCR was used to 
Bioactivity in an aggrecan 32 mer fragment

measure mRNA expression of Mmp13, Il6, Mmp12 and Adamts5 following stimulation of primary mouse chondrocytes with $1-30 \mu \mathrm{M}$ mouse 32 mer peptide $(n=3$ independent pools of cells assayed in duplicate). B) qPCR was also used to measure chondrocyte mRNA expression of Mmp13, Inos, Mmp12 and Adamts5 following stimulation with mouse 32mer peptide, scrambled peptide or $10 \mathrm{ng} / \mathrm{mL}$ IL- $1 \alpha$. The concentration of 32 mer and scrambled peptide was $30 \mu \mathrm{M}(\mathrm{n}=4$ independent pools of cells assayed in duplicate). C) mRNA expression of Mmp13 and $\mathrm{Ccl} 2$ in mouse chondrocytes stimulated with native, glycosylated 32mer was measured by qPCR. The results for each gene are representative of two or more separate experiments.

\section{Figure 2. Decreased mRNA expression of matrix-building genes induced by 32mer} treatment of primary mouse chondrocytes. A) qPCR was used to measure mRNA expression of Col2a1, Matl1, Coll1al and Fmod following stimulation of primary mouse chondrocytes with $30-300 \mu \mathrm{M}$ mouse $32 \mathrm{mer}$ peptide ( $n=2$ independent pools of cells assayed in duplicate). B) qPCR was also used to measure chondrocyte mRNA expression of Col2a, Matl1, Agcn and Fmod following stimulation with mouse 32 mer peptide, scrambled peptide or $10 \mathrm{ng} / \mathrm{mL}$ IL-1 $\alpha$. The concentration of 32 mer and scrambled peptide was $300 \mu \mathrm{M}(\mathrm{n}=2$ independent pools of cells assayed in duplicate). The results for each gene are representative of two or more separate experiments.

Figure 3. Mouse 32mer activity is Myd88-dependent. qPCR was used to measure mRNA expression of A) Mmp12, Mmpl3 and Adamts5 in mouse chondrocytes, B) Mmp12, Mmp13 and $I l 6$ in mouse synovial fibroblasts and C) $I l l \alpha, I l 10$ and $C c l 2$ (I) in mouse peritoneal macrophages derived from wildtype ( $\mathrm{n}=1$ or 2 independent pools of cells assayed in duplicate) or Myd88-deficient ( $\mathrm{n}=1-3$ independent pools of cells assayed in duplicate) mice, and treated 
Bioactivity in an aggrecan 32mer fragment

with mouse 32 mer peptide, scrambled peptide, IL-1 $\alpha$ or LPS. The results are representative of 2 separate experiments.

Figure 4. Mouse 32mer activity is TLR2-dependent. The levels of A) Il6 mRNA expression, B) IL6 protein expression and C) Inos mRNA expression were measured in 3 separate cultures, assayed in duplicate, of macrophage cell lines derived from wildtype or TLR2-deficient mice, treated with mouse 32 mer peptide, scrambled peptide, IL-1 $\alpha$ or LPS. The results are representative of 2 separate experiments.

\section{Figure 5. Human 32mer is pro-catabolic in human chondrocyte cultures and activates} NF-kB via TLR2. A) qPCR was used to assess the effect of human 32 mer and scrambled peptide on the expression of mRNA for human IL6 and human MMP13. B) qPCR was also used to analyse the effect of native, glycosylated 32 mer on the mRNA expression of human CCL2, IL6, MMP3 and MMP13. C) Western blotting was used to assess the effects of human 32mer and scrambled peptide on MMP3 and MMP13 protein expression. D) The stimulatory effects of scrambled, mouse and human 32mer peptides were compared in a TLR2-dependent NF- $\kappa$ B luciferase reporter assay, using the TLR2 agonist, Pam2Cys, as a positive control. 

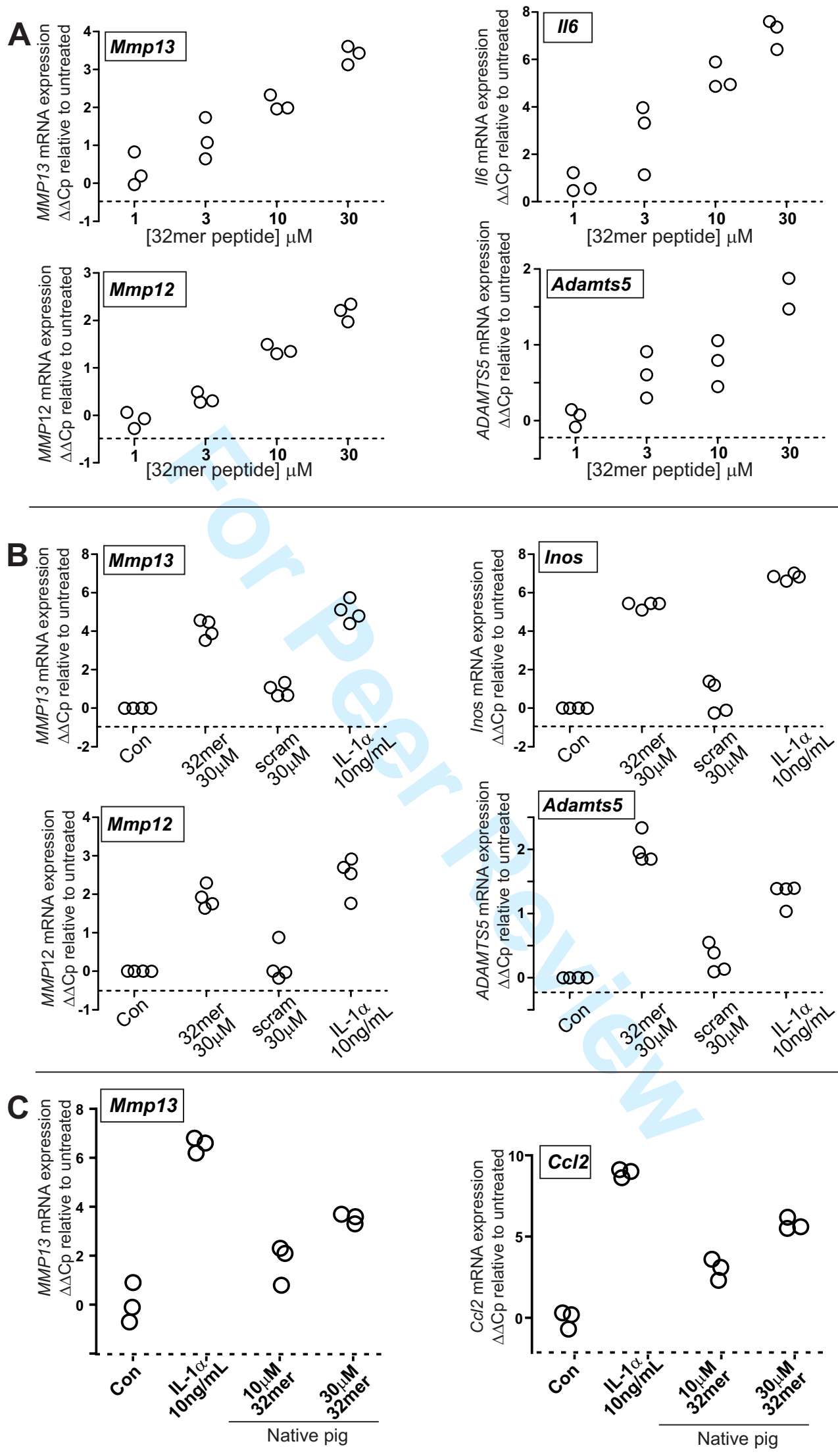

\section{Figure 1}



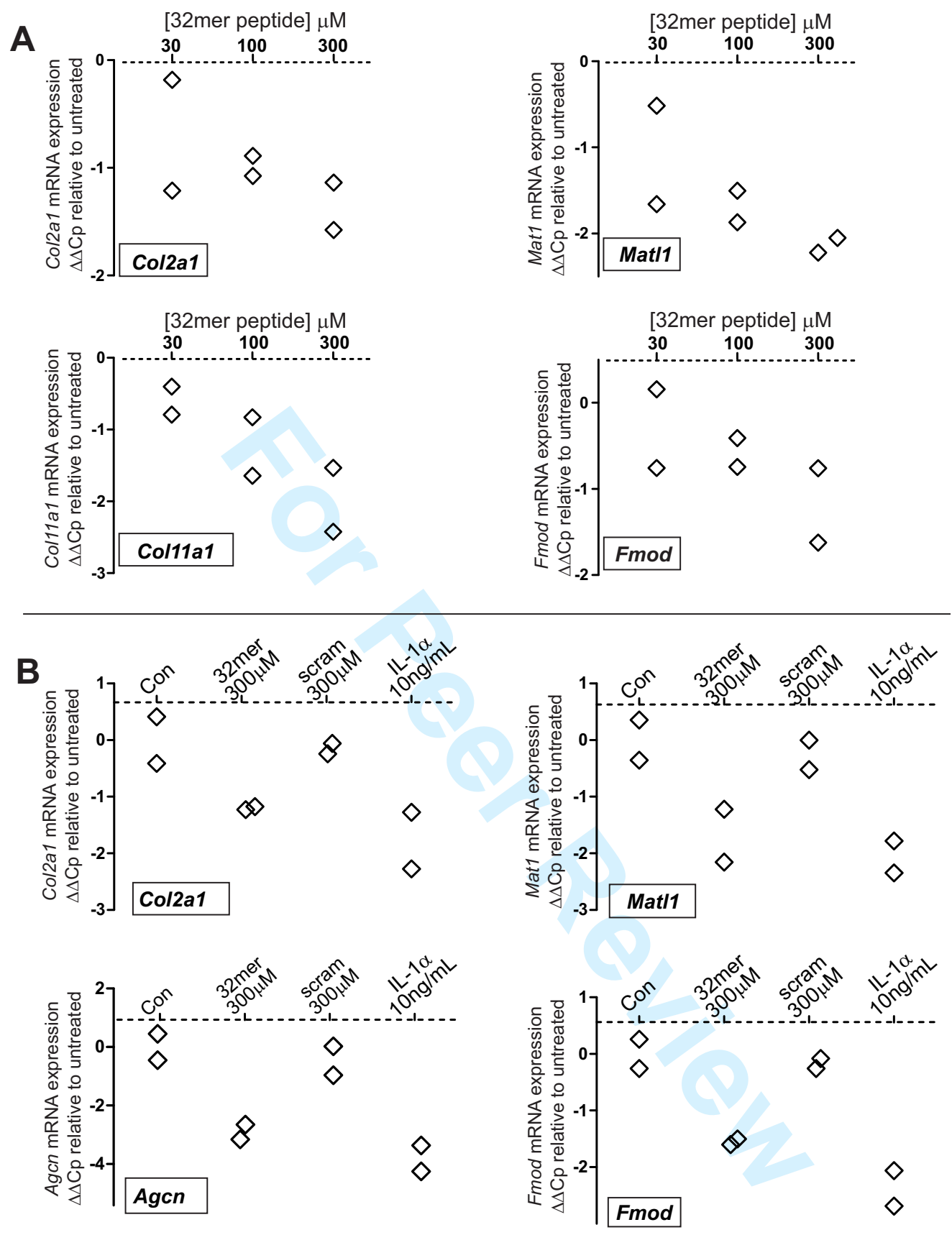

Figure 2 
A Chondrocytes

B Synovial fibroblasts

C Macrophages
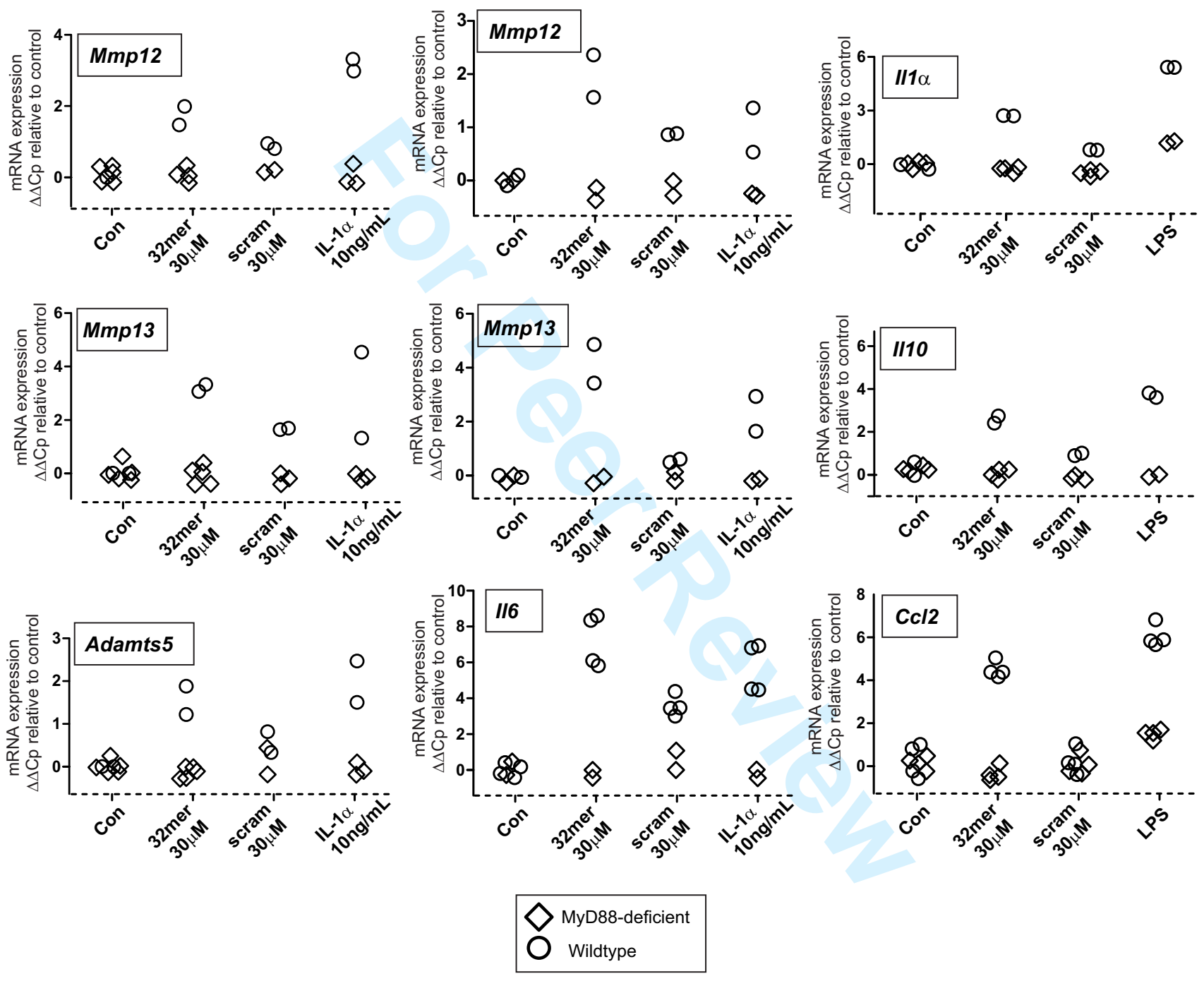

\section{Figure 3}




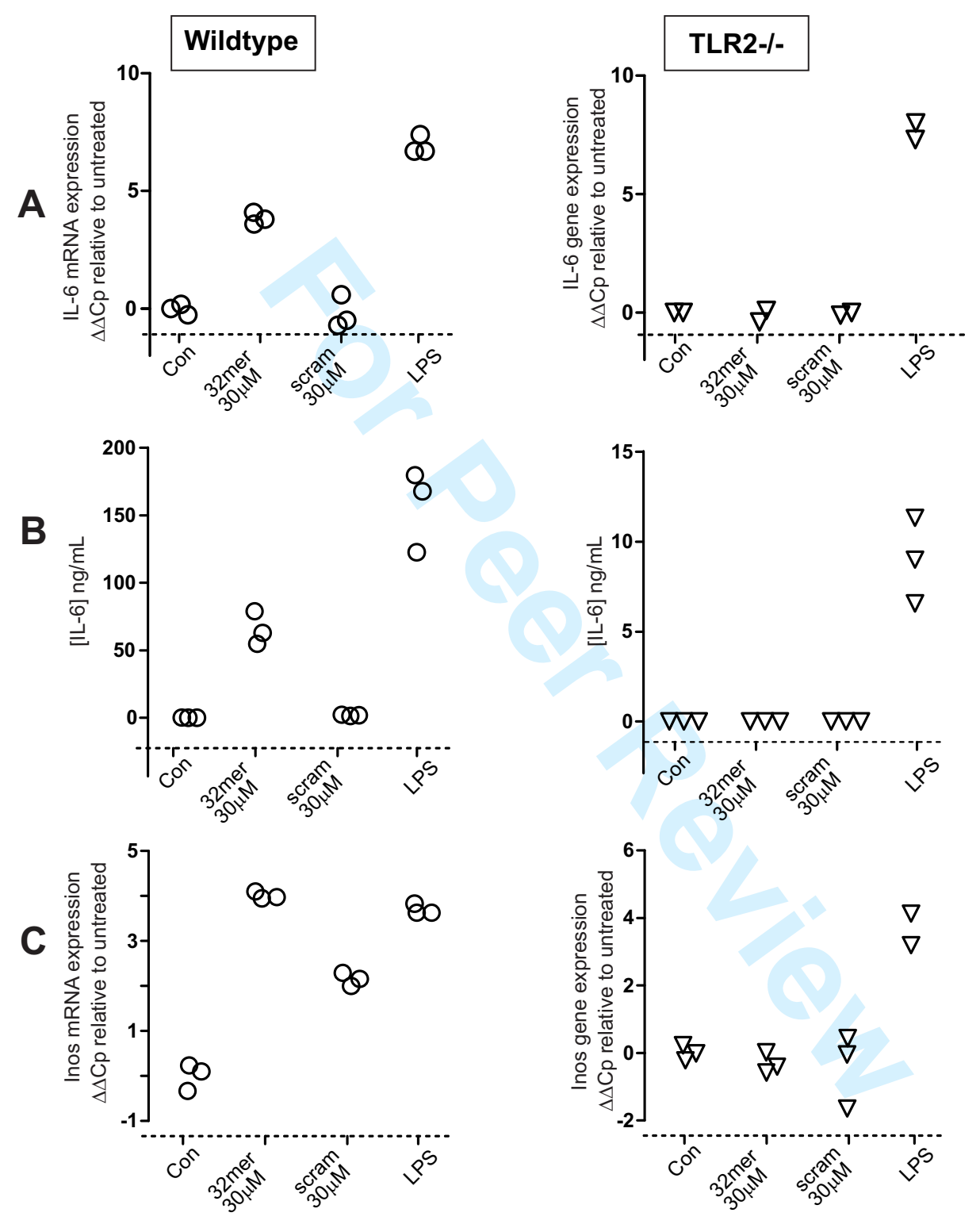

Figure 4 

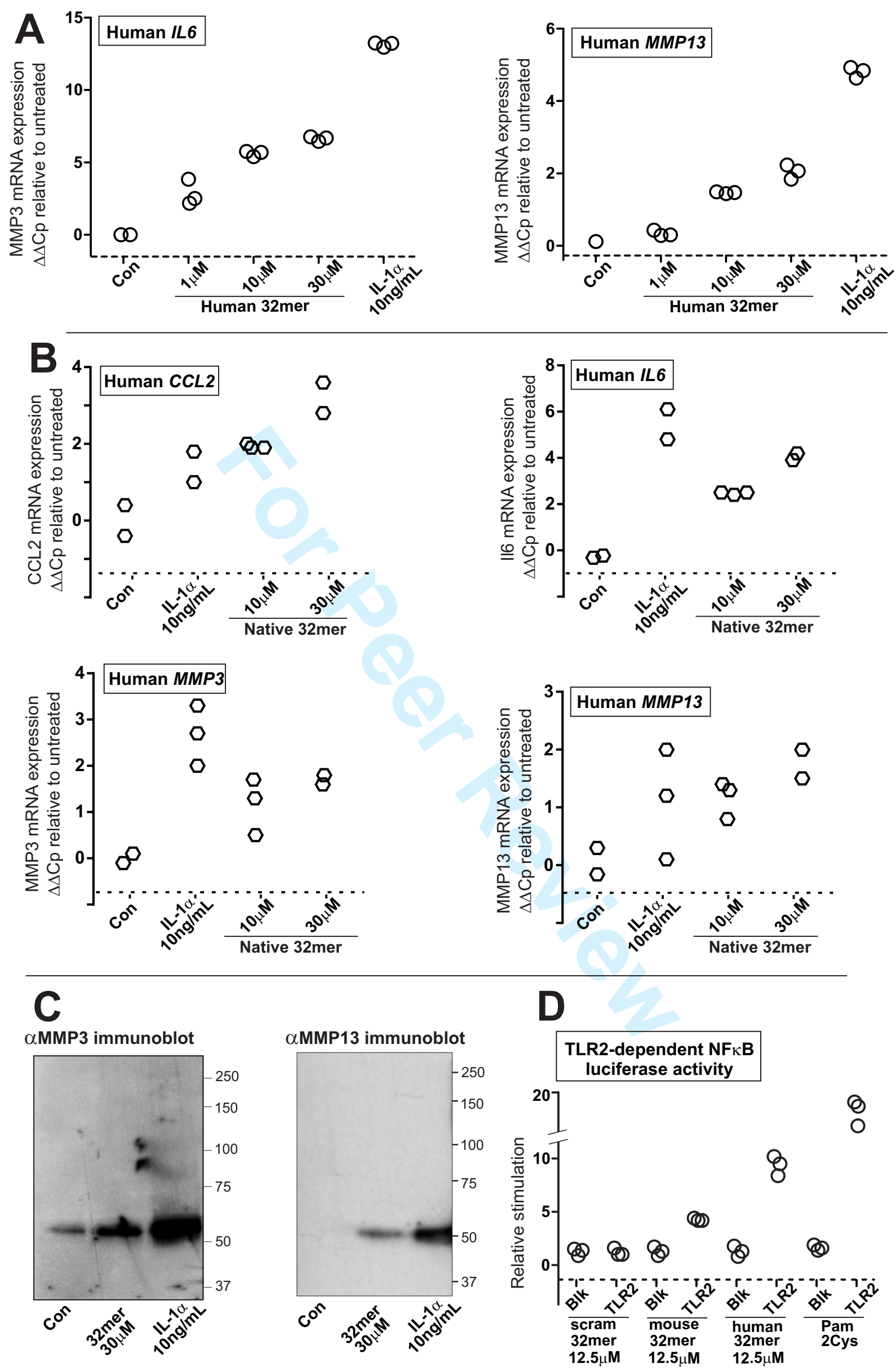

\section{Figure 5}

